\title{
NEW FEATURE
}

\begin{abstract}
- ditors Note: We would like to invite tobacco treatment professionals to share their experiences, such as described below, in order that colleagues everywhere may use and adapt these successful initiatives. This is the first of potentially many formulas for smoking cessation interventions that have been successfully carried out on a small scale.
\end{abstract}

Renee Bittoun, Editor

\section{A protocol for a smoke-free mental health facility}

\author{
Renee Bittoun, Stefan Nynycz, Debbie Ross, Kerry Foley, \\ and Louise Ross \\ Sydney Local Health District, Sydney, Australia
}

It is not uncommon for staff of mental health facilities to have diverging opinions regarding the tobacco use of their patients. Surveys have shown that a significant proportion of staff believe that the smoke free policies are harsh and difficult to implement in health facilities where patient compliance is a matter of serious concern (Lawn, 2004, Wye et al., 2010). Intra-staff disputes and arguments with patients as to how to implement these policies, if at all, occur frequently. This protocol was developed at the request of staff at a mental health facility for HIV AIDS patients afflicted with dementia. Staff were concerned about imminent smoke-free regulations that would impact on their unit.

\section{Background}

Smoking prevalence is high in HIV AIDS patients with > 50\% (Herrmann et al., 2012; Mamary et al., 2002) compared to the $15 \%$ smoking rates in the rest of the Australian population (AIHW, 2011). Smoking has a formidable impact on outcomes in HIV AIDS patients, both on their physical health as well as their mental health (Burns et al., 1996). Of patients with HIV AIDS currently up to $7 \%$ develop dementia (Woods et al., 2009). Unlike other dementias the prevalence of smoking remains relatively high. This group of patients, along with many mental health patients, is considered by many health workers as the most difficult to help with regards smoking cessation (Tesoriero et al., 2010).

In the small facility concerned ( $\mathrm{n}=11), 90 \%$ of the permanent residents with diagnosed HIV AIDS dementia smoked. Patients were agitated and argumentative at times of tobacco distribution, which occurred hourly. When on occasional supervised leave, the buying of tobacco and smoking was a primary concern for the patients and their family or carer. Their smoking was a constant concern and the basis of conflict within the facility.

Conflicts commonly arose between staff, because providing tobacco to patients was contrary to health department policy. Cigarettes were distributed hourly to each smoker by the staff.

The Smoking Cessation Unit was approached by the Nurse Unit Manager (SN) to assess and address the concerns of the staff and to potentially commence a smoking cessation programme for the permanent inpatients.

\section{Methods}

A comprehensive in-service programme was instigated to teach all the staff about smoking, smoking cessation, medical consequences, drug interactions, harm-reduction and cut-down-to-quit strategies and quitting implications on HIV AIDS patients. As The Smoking Cessation Unit has had previous experience in reducing smoking in 'difficult to treat smokers' (Bittoun, 2006), this same protocol was initiated in the facility.

A weaning procedure was put into action to reduce tobacco smoking and increase NRT in its varying forms. Expired Carbon Monoxide (CO) readings were taken daily throughout the NRT regimen to titrate the amount of added NRT (Bittoun, 2010).

Consent for the introduction of this strategy was given by patients, their carers and the state if the patients were 'Wards of the State'. All smoking residents were assessed for tobacco dependence, time to first cigarette, numbers per day and baseline expired carbon monoxide levels were measured. Each smoking patient was offered an individual NRT (Nicotine Replacement Therapy) plan. The NRT ranged from $21 \mathrm{mg}$ nicotine patches to gums, lozenges 


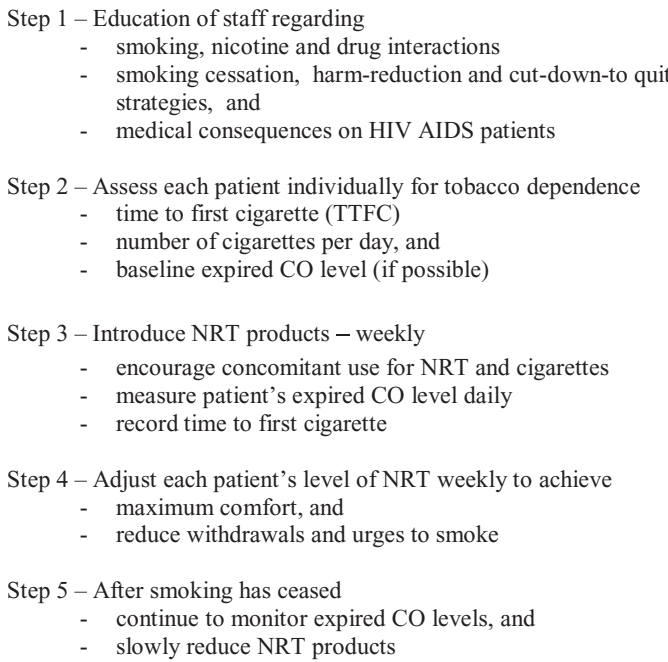

\section{Figure 1}

- Protocol.

and inhalators, with individuals receiving one, some, or all of these nicotine delivery devices as was required. All smoking patients were initially encouraged to smoke concomitantly with NRT.

Over many weekly visits there was a gradual transfer from cigarettes that were dosed every hour to NRT alternating every 2-3 hours. These NRT products were gradually increased to hourly. The weekly face-to-face contact with staff helped to address quickly any problems with the dosing of NRT.

Patients were interested in this method and actively and competitively compared expired CO levels amongst themselves. Patients were assessed weekly and NRT was adjusted in order to achieve maximum comfort and reduce withdrawal symptoms. Over three months allocated tobacco was slowly reduced and entirely replaced with NRT products. Over the following three to six months the NRT products were gradually reduced, and expired CO monitored regularly to confirm self-reported abstinence.

\section{Outcome}

At more than two years no residents continue to smoke, validated by serial expired CO. One resident continues on intermittent NRT. Residents are reported to be less agitated and aggressive, have better physical appearance and have no burns to themselves or their clothing. Family members and carers also report significant positive changes in the behaviour of their charges. Additionally, 15 minutes per hour of staff time is saved due to the abolition of the provision of tobacco.

A protocol has now been developed to initiate this smoking cessation regimen for any new residents prior to admission (Figure 1).

\section{Discussion}

Previously feuding staff of this unit are overwhelmingly delighted in the outcome as they are no longer custodians of tobacco smoking paraphernalia or subject to the cyclic agitation for tobacco from their patients.

This is a very positive outcome and sees the application of an initial 'cutting down to stop' strategy that might be adaptable in many difficult circumstances where smoking patients are compelled to quit (Bittoun et al., 2010)

\section{Financial Support}

This research received no specific grant from any funding agency, commercial or not-for-profit sectors.

\section{Conflict of Interest}

Renee Bittoun, over her career, has advised and received grants from pharmaceutical companies, government and non-government agencies that produce smoking cessation products. Other authors' conflicts of interest: None

\section{Ethical Standards}

The authors assert that all procedures contributing to this work comply with the ethical standards of the relevant national and institutional committees on human experimentation and with the Helsinki Declaration of 1975, as revised in 2008 .

\section{References}

AIHW 2011.2010. National Drug Strategy Household Survey report. Drug statistics series. no. 25. Cat. no. PHE 145. Canberra: AIHW.

Bittoun, R. 2006. A combination Nicotine Replacement Therapy (NRT) algorithm for hard-to-treat smokers. Journal of Smoking Cessation, 1, 3-6.

Bittoun, R., Nynycz, S., Ross, D., Foley, K. \& Ross, L. 2010. Implementing a smokefree policy in an inpatient HIV AIDS dementia residential facility. Drug and Alcohol Review, 29, $7-7$.

Burns, D.N., Hillman, D., Neaton, J.D., Sherer, R. 1996. Cigarette smoking, bacterial pneumonia, and other clinical outcomes in HIV-1 infection. Journal of Acquired Immune Deficiency Syndromes and Human Retrovirology, 13, 374383.

Herrmann, S.E., Mckinnon, E.J., Williams, L.J., John, M. 2012. Use of alcohol, nicotine and other drugs in the Western Australian HIV Cohort study. Sex Health, 9, 199201.

Lawn, S.J. 2004. Systemic barriers to quitting smoking among institutionalised public mental health service populations: A comparison of two Australian sites. International Journal of Social Psychiatry, 50, 204-215. 
Mamary, E.M., Bahrs, D. \& Martinez, S. 2002. Cigarette smoking and the desire to quit among individuals living with HIV. Aids Patient Care and Stds, 16, 39-42.

Tesoriero, J.M., Gieryic, S.M., Carrascal, A. \& Lavigne, H.E. 2010. Smoking among HIV positive New Yorkers: prevalence, frequency, and opportunities for cessation. Aids and Behavior, $14,824-835$.
Woods, S.P., Moore, D.J., Weber, E. \& Grant, I. 2009. Cognitive neuropsychology of HIV-associated neurocognitive disorders. Neuropsychology Review, 19, 152-168.

Wye, P., Bowman, J., Wiggers, J., Baker, A., Knight, J. 2010. Total smoking bans in psychiatric inpatient services: a survey of perceived benefits, barriers and support among staff. Bmc Public Health, 10. 